\section{Influence of Experience on the Sensitivity to Discomfort}

THE sensitivity of a subject to discomfort arising degree on his familiarity with, or technical knowledge of, the environment. Some evidence to this effect has accumulated from a long series of field-studies of lighting. A subject may be unconscious of glare from a bare lamp over his desk until his attention is directed to it, but thereafter may become aware of glare-discomfort in other environments as well. Other workers have recorded similar effects ${ }^{1}$.

It was decided to test the existence of this sensitization using the apparatus of the 'control experiment' of a 'multiple criterion' study ${ }^{2}$. Two individuals were selected who were quite unfamiliar with lighting and glare technology, but who were intelligent in their general approach to perceptual problems. Preliminary assessments showed that they were relatively insensitive to discomfort from glare.

Each observer was then asked to make settings of the environment to give certain degrees of glarediscomfort under controlled conditions, and these assessments were repeated day after day for several weeks. Other subjects who were familiar with the experiment and its technology, and who were therefore in the 'sensitized' condition, performed the same assessments over a similar period (but the readings were not concurrent). The accompanying graph shows the observations of one such 'experienced' subject, and of one of the test subjects, over this period.

It is clear that, although at first the settings of the experienced subject and the test subject differed considerably, the test subject being less sensitive to glare than the experienced subject, as the test proceeded the test subject developed a sensitivity which approached that of the experienced subject (the other test subject showed the same trend). The

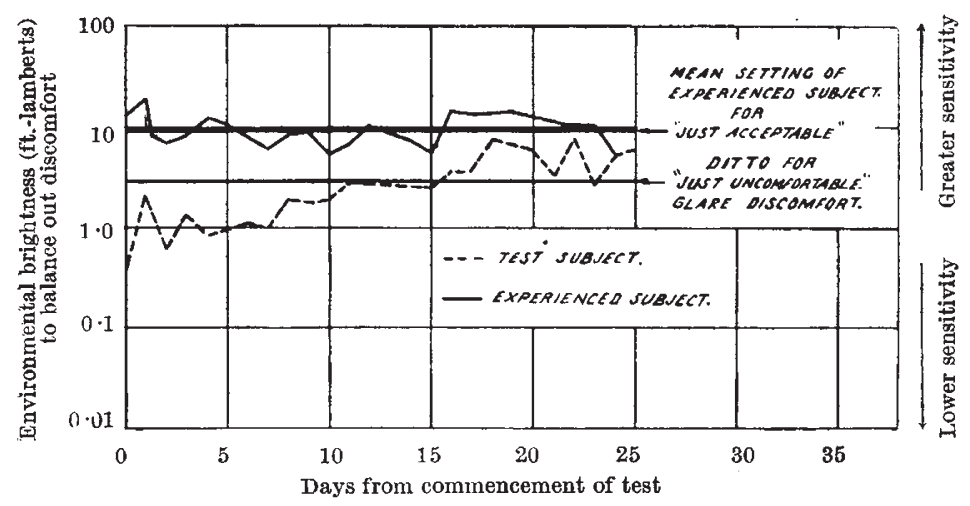

Glare-discomfort assessments (glare sources of flxed area and brightness) under unaware? from his environment may be dependent in some

body of untrained subjects. The designer of an environment (for example, a building, a lighting or heating installation) must therefore decide whether to plan for the low sensitivity of the 'average man', or set himself the higher and more consistent standard of the experienced observer, who will, of course, be his only informed critic.

One is left with a question. In what way are individuals affected, in health or efficiency, by physical conditions which cause them no conscious discomfort, but which produce sharp reactions in the experienced subject ? Will these conditions have an influence after a day's work, or a year's work ? Will children, working under the heating and lighting conditions still characteristic of some of our older schools, suffer ill-effects from factors of which they are usually quite

Building Research Station, Garston,

\section{R. G. HOPXINSON}

Watford, Herts. July 28.

${ }^{1}$ Christopher, H. N., J. Soc. Motion Pict. Tel. Eng., 56, 369 (1951). ${ }^{2}$ Hopkinson, R. G., Quart. J. Exp. Psych., 2, 124 (1950).

Hopkinson, R. G., Trans. Illum. Eng. Soc. (London), 5, 1 (1940).

Petherbridge, P., and Hopkinson, R. G., Trans. Illum. Eng. Soc. (London), 15, 39 (1950).

\section{A Small Insect Enclosed in an Atmospheric Ice Crystal}

INSECTS have been subjected to simulated upper air conditions, and the death of soft-bodied forms artificially coated with jce has been discussed ${ }^{1}$. However, I know of no previous record of an insect enclosed in a natural atmospheric ice crystal. A fall of ice crystals was observed in Banff National Park, Alberta, during the early evening of May 4, 1951, and one of the crystals contained a minute adult male chironomid. Weather associated with this record is described below.

Polar continental air occupied the area, and the day had been clear. At $1645 \mathrm{hr}$. (Mountain Standard Time), a small banner cloud was observed forming on the lee side of Bident Mountain. The cloud formed at the top of a sunlit slope at an altitude between 7,800 and $8,200 \mathrm{ft}$. During the period of its growth, between 1645 and 1950 M.S.T., the air temperature in the valley bottom changed from $49^{\circ} \mathrm{F}$. to $42^{\circ} \mathrm{F}$., and the relative humidity from 57 to 64 per cent. At 1945 M.S.T., shortly before the cloud reached its maximum development, the fall of ice crystals began, and persisted for ten minutes. The fall deposited small amounts of ice over an area much larger than that directly under the cloud.

experienced subject held his criterion unchanged over a period of the test (in fact, over a period of more than two years). The precise experimental conditions are described elsewhere ${ }^{2-4}$.

Previous experiment has shown clearly that intelligent subjects can hold a criterion of sensation over long periods, and can therefore act as 'human meters' of the physical factors which govern the reactions of man to his environment. They are, however, in general, although not always, more sensitive, both to changes in the environment and to the effects of the environment on their sensations, than is the 'average man', that is, the norm of the
The crystals were needle-shaped, about six millimetres long, and some were branched. The chironomid was found enclosed in one of the branched crystals; but the crystal shape was not altered by its inclusion. The insect did not recover when the crystal was melted at room temperature. Presumably, the insect was carried to the level of ice formation by the updraught on the heated slope.

Forest Insect Laboratory,

W. R. HENSON

Ontario. July 30 .

${ }^{1}$ Wellington, W. G., Canad. Ent., 77, (7), 44 (1945).
Sault Ste. Marie, 